\title{
Changes in ocean circulation and carbon storage are decoupled from air-sea $\mathrm{CO}_{2}$ fluxes
}

\author{
I. Marinov ${ }^{1,2}$ and A. Gnanadesikan ${ }^{3,4}$ \\ ${ }^{1}$ Department of Earth and Environmental Science, University of Pennsylvania, 240 S. 33rd Street, \\ Hayden Hall 153, Philadelphia, PA 19104, USA \\ ${ }^{2}$ Department of Marine Chemistry and Geochemistry, Woods Hole Oceanographic Institution, \\ 266 Woods Hole Road, Woods Hole, MA 02543, USA \\ ${ }^{3}$ Geophysical Fluid Dynamics Lab (NOAA), 201 Forrestal Road, Princeton, NJ 08540, USA \\ ${ }^{4}$ Department of Earth and Planetary Sciences, Johns Hopkins Univ., Baltimore, MD, USA
}

Received: 6 October 2010 - Published in Biogeosciences Discuss.: 1 November 2010

Revised: 28 January 2011 - Accepted: 7 February 2011 - Published: 25 February 2011

\begin{abstract}
The spatial distribution of the air-sea flux of carbon dioxide is a poor indicator of the underlying ocean circulation and of ocean carbon storage. The weak dependence on circulation arises because mixing-driven changes in solubility-driven and biologically-driven air-sea fluxes largely cancel out. This cancellation occurs because mixing driven increases in the poleward residual mean circulation result in more transport of both remineralized nutrients and heat from low to high latitudes. By contrast, increasing vertical mixing decreases the storage associated with both the biological and solubility pumps, as it decreases remineralized carbon storage in the deep ocean and warms the ocean as a whole.
\end{abstract}

\section{Introduction}

The ocean carbon cycle plays a critical role in setting today's climate by determining the partitioning of carbon between the atmosphere and ocean. Two natural ways of characterizing this cycle are the meridional transport and the vertical profile of carbon within the ocean. The north-south gradient of the meridional transport of carbon is primarily balanced by air-sea fluxes of carbon dioxide, leading to the obvious question of whether measuring such fluxes (e.g., Takahashi et al., 2009) would provide important constraints on ocean circulation or carbon storage. Using a suite of ocean circulation models with different parameterizations of interior mix-

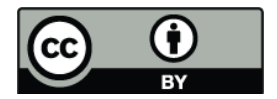

Correspondence to: I. Marinov

(imarinov@sas.upenn.edu) ing, we show that the air-sea $\mathrm{CO}_{2}$ flux is insensitive to the circulation, in contrast to the storage of carbon by the ocean.

We analyze this contrasting behavior in terms of the oceanic solubility and biological pumps of carbon. Cold high latitude surface waters hold more dissolved inorganic carbon (DIC) than warm, low-latitude waters. The solubility pump is the result of processes whereby these cold waters sink, injecting $\mathrm{CO}_{2}$ into the deep ocean (Volk and Hoffert, 1985). The biological pump is associated with the production of planktonic organic matter at the ocean surface and the transport and subsequent decomposition of biogenic material throughout the water column, resulting in a further enhancement of deep carbon concentrations.

The extent to which changes in ocean ventilation impact the natural carbon pumps and air-sea $\mathrm{CO}_{2}$ exchange has featured prominently in recent a number of recent papers. Changes in the rate of convection and deep water formation in the Southern Ocean have been shown to strongly impact the oceanic biological pump and atmospheric $p \mathrm{CO}_{2}$ (e.g. Marinov et al., 2008a, b) and have been invoked to drive glacial-interglacial changes in atmospheric $p \mathrm{CO}_{2}$ (e.g. Sarmiento and Toggweiler, 1984; Anderson et al., 2009; Toggweiler et al., 2006; Sigman et al., 2010). In an intriguing new study Le Quere et al. (2007) suggest that changes in Southern Ocean ventilation associated with increased Westerlies have already resulted in a loss of biologically sequestered $\mathrm{CO}_{2}$ from the deep ocean via increased Southern Ocean upwelling and a weakening of the natural biological pump.

In this paper, we use a suite of models in which the vertical mixing coefficient $K_{\mathrm{v}}$ and the lateral mixing coefficient $A_{\mathrm{I}}$ are varied, producing a range of ocean circulation. We show

Published by Copernicus Publications on behalf of the European Geosciences Union. 
that while these changes produce compensating responses in the air-sea fluxes associated with the solubility and biological pumps, they do not produce a compensation in the inventories of carbon associated with these pumps. As a result, the total air-sea $\mathrm{CO}_{2}$ flux is decoupled both from ocean circulation and from the storage of carbon within the ocean.

\section{Methods}

Our suite of simulations was made with the Geophysical Fluid Dynamics Laboratory Modular Ocean Model (MOM) version 3 and has previously been used for a number of biogeochemical dynamics studies (Gnanadesikan et al., 2002, 2004; Marinov et al., 2006, 2008a, b). The biogeochemistry component follows OCMIP-2 specifications (Najjar et al., 2007), with new biological production calculated by restoring our limiting nutrient $\mathrm{PO}_{4}$ to observations $\mathrm{PO}_{4}$,obs at each time step $t$, whenever $\mathrm{PO}_{4}>\mathrm{PO}_{4, \text { obs }}$ :

$$
\begin{aligned}
& J_{\text {prod }}(x, y, z, t)=\left(\mathrm{PO}_{4}(x, y, z, t)\right. \\
& \left.\quad-\mathrm{PO}_{4, \text { obs }}(x, y, z, t)\right) / \tau \text { for } z<75 \mathrm{~m}
\end{aligned}
$$

where $\tau$ is the biological time scale, $x, y, z$ are model longitude, latitude and depth and $t$ is the time. Globally integrated $\mathrm{PO}_{4}$ is set constant in all experiments. Air-sea gas exchange of carbon dioxide and oxygen is parameterized following Wanninkhof (1992).

The use of this simple biogeochemical model means that nutrient uptake at the surface is tightly coupled to nutrient supply and that surface nutrient concentrations remain relatively constant when the circulation changes. This relative constancy has proved useful in analyzing the dynamics of ocean carbon storage, allowing us to distinguish the separate impacts of changes in surface nutrients and circulation on ocean carbon storage (Marinov et al., 2008b). However, it should be recognized that in the real world nutrient supply and uptake may not be so tightly coupled. For example, if the rate of nutrient uptake in the subpolar North Pacific is set by the rate of aeolian iron deposition, an increase in macronutrient supply due to deep mixing would result in an increase in surface nutrients not captured by this biogeochemical framework.

Four different implementations of MOM3 are analyzed here.

- Our "Control" is a model with relatively low $A_{\mathrm{i}}$ and $K_{\mathrm{v}}$. The diapycnal mixing coefficient $K_{\mathrm{v}}$ varies hyperbolically from $0.15 \mathrm{~cm}^{2} \mathrm{~s}^{-1}$ at the surface to $1.3 \mathrm{~cm}^{2} \mathrm{~s}^{-1}$ at $5000 \mathrm{~m}$, and the isopycnal mixing coefficient $A_{\mathrm{i}}$ is set to $1000 \mathrm{~m}^{2} \mathrm{~s}^{-1}$ everywhere in the ocean.

- In the high $K_{\mathrm{v}}$ model, $K_{\mathrm{v}}$ varies hyperbolically from $0.6 \mathrm{~cm}^{2} \mathrm{~s}^{-1}$ at the surface to $1.3 \mathrm{~cm}^{2} \mathrm{~s}^{-1}$ at $5000 \mathrm{~m} \mathrm{ev}-$ erywhere in the ocean, while $A_{\mathrm{i}}$ is as in the Control model.
- In the high $A_{\mathrm{i}}$ model $K_{\mathrm{v}}$ is as in the Control model, but $A_{\mathrm{i}}$ is set to $2000 \mathrm{~m}^{2} \mathrm{~s}^{-1}$.

- In the high $A_{\mathrm{i}}$-high $K_{\mathrm{v}}$ model, $A_{\mathrm{i}}$ is $2000 \mathrm{~m}^{2} \mathrm{~s}^{-1}$ and $K_{\mathrm{V}}$ is as in the high $K_{\mathrm{v}}$ model. As discussed in Gnanadesikan et al. (2002), this combination of $A_{\mathrm{I}}$ and $K_{\mathrm{v}}$ produces a pycnocline depth that largely matches that in the Control run, but a meridional overturning circulation with a substantially different structure.

Wind stresses for all of these models are taken from the Hellermann and Rosenstein (1983) product and surface fluxes of heat and moisture are a combination of applied fluxes from the da Silva et al. (1994) dataset and flux corrections derived by restoring the surface temperature and salinity back to observations. As with the biological model, this means that the primary effect of changes in mixing is to change the interior circulation rather than the surface conditions. As shown in Gnanadesikan et al. (2003) the modeled Southern Hemisphere circulation and tropical upwelling agree reasonably well with the predictions of the theory of Gnanadesikan (1999), suggesting that numerical diffusion plays a relatively weak role in these simulations. This is likely because the forcing varies relatively smoothly over time and the advection scheme is relatively non-diffusive.

Each of these models is run in three configurations that allow us to isolate the impacts of the biological and solubility effects on the carbon pump. In the ABIOTIC run biology is turned off (Murnane et al., 1999), and the alkalinity depends only on salinity so that the resulting $\mathrm{CO}_{2}$ distribution and airsea $\mathrm{CO}_{2}$ fluxes depend only on temperature and salinity. In the BIOTIC run we turn the solubility pump off by setting the ocean temperature and salinity constant everywhere at the surface in the calculation of the air-sea $\mathrm{CO}_{2}$ exchange calculation. Finally, in the FULL configuration we turn on biology such that the resulting $\mathrm{CO}_{2}$ distributions and fluxes depend on both biological and solubility effects.

\section{Results and discussion}

Subgridscale mixing and resulting changes in ocean circulation have a major impact on the natural carbon pumps and on the solubility and biological air-sea $\mathrm{CO}_{2}$ fluxes after full equilibration of the ocean-atmosphere carbon system has been achieved. Figure 1 shows results from our 4 models run in the ABIOTIC, BIOTIC and FULL configurations. The surface to deep gradients in DIC in each of these configurations are representative of the strength of the solubility pump (Fig. 1a), the biological pump (Fig. 1d) and the full carbon pump (Fig. 1g) at equilibrium. Figure 1 supports our contention that the linear separation of total DIC and total carbon pumps into components works well, at least in the global average, since the sum of the solubility pump (Fig. 1a) and biological pump (Fig. 1d) closely approximates the total 

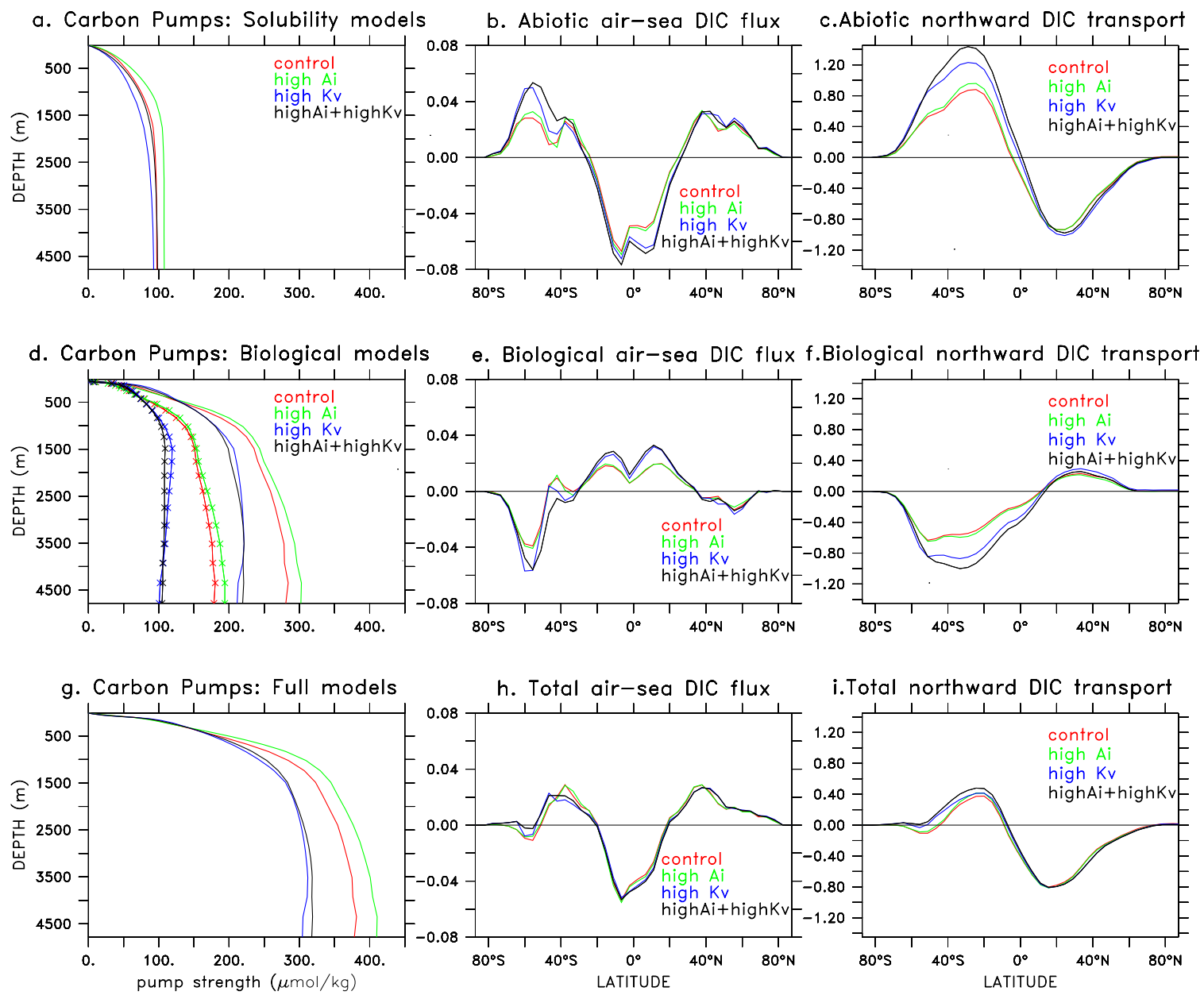

i.Total northward DIC transport

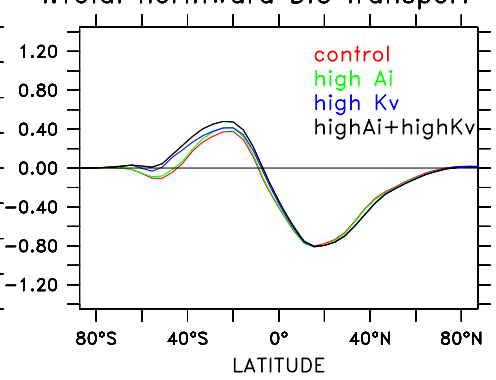

Fig. 1. Carbon pumps ( $\left.\mu \mathrm{mol} \mathrm{kg}{ }^{-1}\right)$, air-sea carbon fluxes $\left(\mathrm{PgC} \mathrm{yr}^{-1} \mathrm{degree}^{-1}\right)$ and northward carbon transports $\left(\mathrm{PgC} \mathrm{yr}^{-1}\right)$ in $4 \mathrm{models}$ with different mixing. Top panels (a-c): abiotic carbon pump, air-sea DIC flux (positive fluxes are into the ocean) and northward DIC transport integrated over the entire watercolumn from the ABIOTIC models. Middle panels (d-f): biological carbon pump, air-sea DIC flux and transport from the BIOTIC only models. Bottom panels (g-i): total (full) carbon pump, air-sea DIC flux and transports from the FULL model configurations which include both biotic and solubility pumps. Fluxes and transports are zonal and annual mean averages. Pumps represent the zonally and meridionally integrated DIC at each depth minus average surface DIC in $\mu \mathrm{mol} \mathrm{kg}^{-1}$. For each model, the total or full carbon pump (g) is well approximated by the sum of the abiotic (a) and biological (d) carbon pumps. Starred lines in panel (d) show remineralized carbon (calculated as remineralized nutrients times $r_{\mathrm{C}: \mathrm{P}}=117$ ); surface-to-deep gradients in remineralized carbon represent the organic or soft tissue pump strength assuming equilibrium with the atmosphere. Differences between the starred and unstarred lined in panel (d) are due to carbonate and disequilibrium with the atmosphere. Intermodel differences in biological carbon pumps (unstarred lines in panel d) can be explained by intermodel differences in remineralized carbon (starred lines in panel d), as discussed in the text.

carbon pump (Fig. 1g). Figure 1 also shows the abiotic, biological and total air-sea $\mathrm{CO}_{2}$ fluxes (middle column) and transports (right hand column) corresponding to the pumps in the left hand column. Note that the biological pump gradient is due to a combination of soft tissue export associated with nutrient transport to the deep (the so-called soft tissue or organic pump) and carbonate mineral export (the carbonate pump) and is enhanced by the slow rate of air-sea gas exchange (Toggweiler et al., 2003b). Starred lines in Fig. 1d show the contribution to the biological pump due to the soft tissue pump assuming surface $\mathrm{CO}_{2}$ is in equilibrium with the atmosphere, i.e., this is the zonally and meridionally averaged respired carbon calculated from the remineralized nutrients multiplied by a C:P stoichiometric ratio, assumed to be a constant in all our models.

Two important results emerging from Fig. 1 are:

I. An increase in $K_{\mathrm{v}}$ decreases the ocean carbon storage associated with both biological and solubility carbon pumps. The two effects reinforce each other, such that total carbon storage decreases with larger $K_{\mathrm{v}}$.

II. An increase in $K_{\mathrm{v}}$ increases the magnitude of both the biological and the abiotic air-sea fluxes. The two effects 
Control

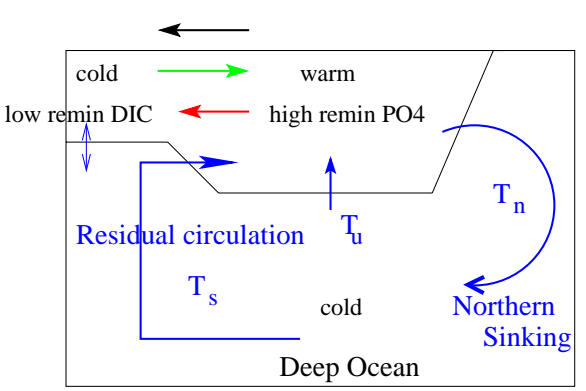

high Kv model

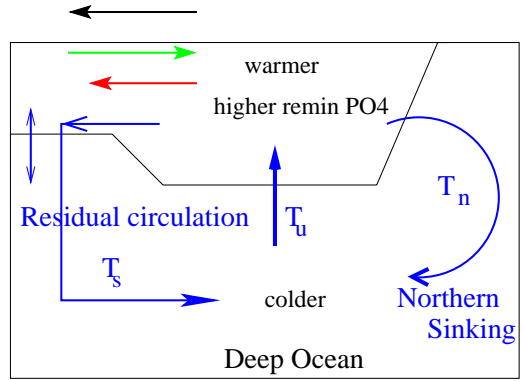

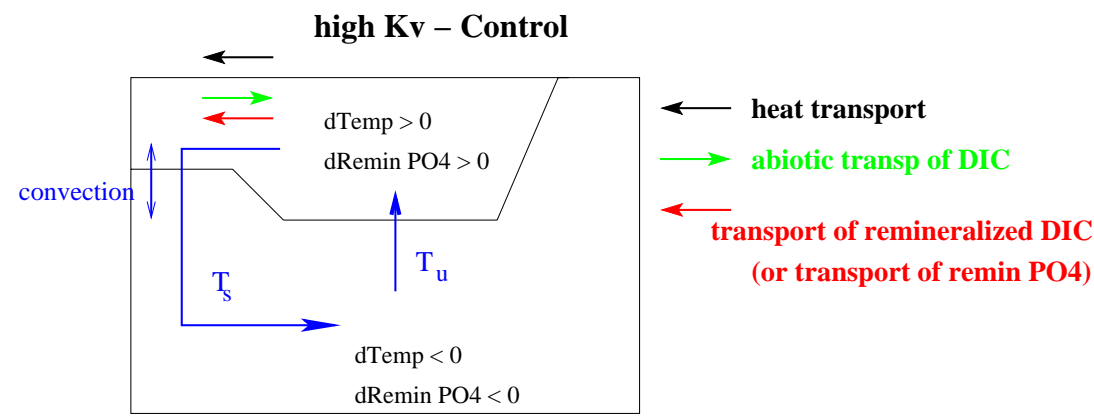

Southern Ocean

Equator

Northern Oceans

Fig. 2. Schematic showing the impact of increased diapycnal mixing on circulation and the transport of abiotic DIC and remineralized $\mathrm{PO}_{4}$ in our GCM. Changes in the abiotic DIC transport and biological DIC transport cancel each other out. The total (abiotic + biological) DIC transport is similar in the control and high $K_{\mathrm{v}}$ models and is northward.

compensate each other, such that the total air-sea $\mathrm{CO}_{2}$ flux changes little.

The impact of changing diapycnal and isopycnal mixing on oceanic circulation and oceanic heat transport is summarized in Fig. 2 (see also Gnanadesikan, 1999, 2003 and Marinov et al., 2008b). Increasing vertical mixing $K_{\mathrm{v}}$ affects oceanic circulation in 2 major ways:

A. Changing the mean hydrographic structure. This involves increasing the relative contribution of the Southern Ocean waters to the deep ocean via increased Southern Ocean convection and AABW formation (blue arrow in Fig. 2) as well as increasing the depth of the tropical pycnocline.

B. Changing the residual mean circulation ( $T_{S}$ in Fig. 2). In detail, increasing $K_{\mathrm{v}}$ increases the conversion from dense to light water in the tropics and also increases the thermocline depth as more heat diffuses downwards. This in turn increases the southward eddy transport and the Northern Hemisphere overturning $T_{n}$ and thus increases poleward transport of light waters and heat in both hemispheres.

We will invoke mechanism A to explain most of the observed carbon pump differences among models (Result (I) above), while arguing that mechanism (B) dominates the air-sea flux differences among models (Result (II) above).

We begin by looking at the impact of vertical mixing on ocean carbon storage associated with the solubility pump. As seen in Fig. 3a, increasing vertical mixing produces an increase in the importance of Southern Ocean source waters causing temperatures to decrease along the AABW pathway and in the deep ocean below $2500 \mathrm{~m}$, and enhancing the storage of carbon in these waters. However, in low latitudes higher mixing also results in deeper penetration of surface heat, increasing temperatures above $2500 \mathrm{~m}$ depth. This warming translates into less net storage of abiotic DIC in the ocean as a whole (Fig. 3a, c), and thus a less efficient solubility pump in the high $K_{\mathrm{v}}$ compared to the control model (Fig. 1a). The three dimensional pattern of abiotic DIC change is well correlated with the temperature change, with a slope of $-8.5 \mu \mathrm{M} \mathrm{DIC} \mathrm{K}^{-1}$.

We note that temperature changes alone give an indication of the strength of the solubility pump assuming infinitely fast gas exchange, i.e., surface $\mathrm{CO}_{2}$ in equilibrium with the atmosphere. As discussed in Toggweiler et al. (2003a), slow gas exchange of $\mathrm{CO}_{2}$ makes the solubility pump less efficient at storing carbon. Slow gas exchange slightly enhances the response of the solubility pump to changes in mixing, so that a more convectively ventilated ocean tends to have less carbon 

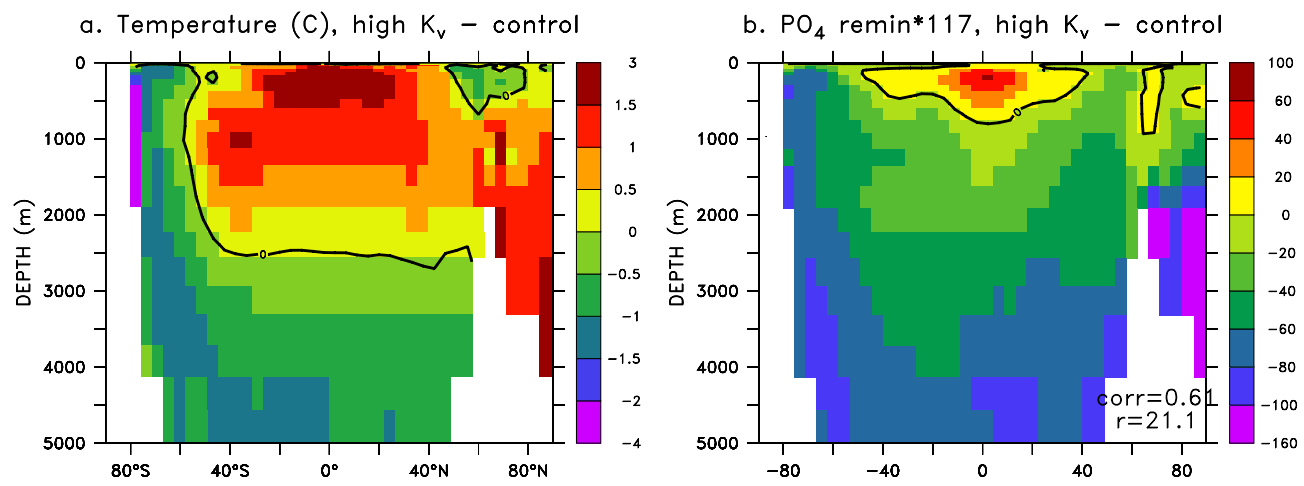

c. Abiotic DIC, high $\mathrm{K}_{\mathrm{v}}-$ control
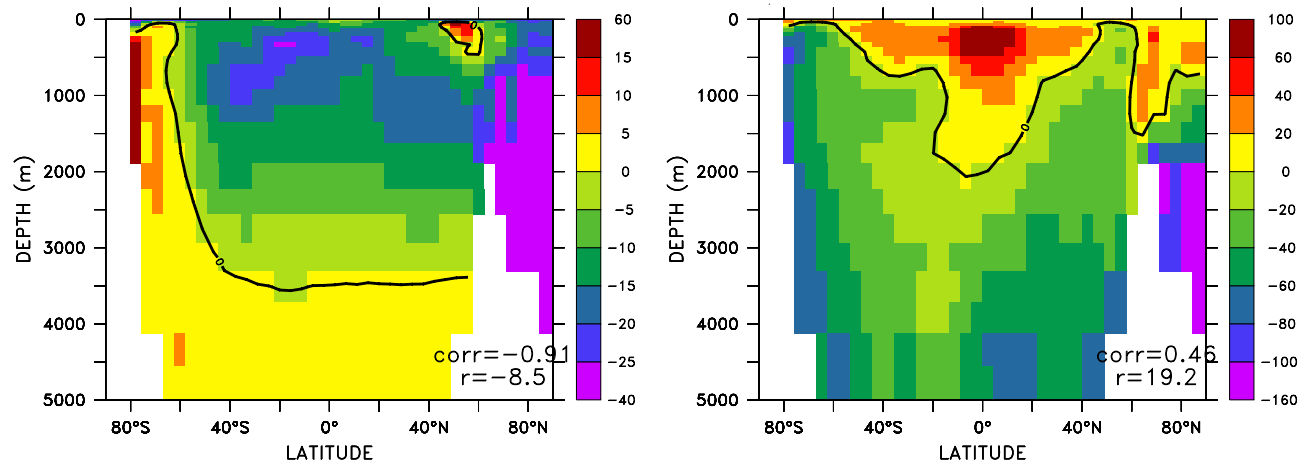

Fig. 3. Zonally averaged annual mean differences between the high $K_{\mathrm{V}}$ and control models: (a) temperature $\left({ }^{\circ} \mathrm{C}\right)$, (b) remineralized DIC $\left(\mu \mathrm{mol} \mathrm{kg}{ }^{-1}\right.$ ) calculated as remineralized $\mathrm{PO}_{4}$ (model tracer) times 117 . (c) Salinity normalized DIC ( $\mu \mathrm{mol} \mathrm{kg}^{-1}$ ) from the ABIOTIC run, (d) biological DIC calculated from BIOTIC runs $\left(\mu \mathrm{mol} \mathrm{kg}^{-1}\right)$. Small differences between $\mathrm{b}$ and $\mathrm{d}$ are due to intermodel differences in air-sea surface $\mathrm{CO}_{2}$ disequilibrium. Correlations (corr) and regression coefficients $(r)$ with the temperature difference in panel (a) are shown in each case. Globally, remineralized DIC is well correlated to temperature (corr $=0.61$ ). Abiotic DIC differences are due primarily to intermodel differences in temperature (corr $=-0.91$ ), and to a lesser extent to intermodel salinity differences.

than would be expected from the temperature change alone (notice the difference between the zero lines in Fig. 3a and c).

Turning next to the ocean carbon storage associated with biology, we begin by reviewing the nutrient dynamics that underlie this storage. Everywhere in the ocean our biologically limiting nutrient is the sum of a preformed and a remineralized component. Preformed nutrients are the nutrients that sink into the ocean interior without having been utilized in photosynthetic production at the ocean surface; they signal an inefficient biological pump (Ito and Follows, 2005; Marinov et al., 2006). Remineralized nutrients are those respired throughout the water column and are stoichiometrically associated with remineralized carbon. The deep ocean is ventilated by the Southern Ocean and the NADW. The Southern Ocean has relatively higher preformed nutrients (i.e., a more inefficient biological pump) and lower sea surface temperature (SST).

Increasing $K_{\mathrm{V}}$ makes the deep ocean look more like the Southern Ocean, decreasing preformed nutrients throughout the deep ocean. The consequences are a "leakier" or less efficient biological carbon pump in the high $K_{\mathrm{v}}$ model compared to the control LL model (see also Marinov et al., 2008b). For a constant total phosphate, an increase in preformed nutrient will correspond to a decrease in remineralized nutrient (Fig. 3b) and carbon (Fig. 3d) along the AABW pathway and in the deep ocean. Circulation-induced changes in remineralized nutrients and carbon explain intermodel differences in the total biological pump (compare starred and unstarred lines in Fig. 1d).

Taking the two pumps (solubility and biological) together, lower total remineralized inventory and overall warmer temperatures mean that the high vertical mixing (high $K_{\mathrm{V}}$ ) model stores less carbon than the control model in the ocean. Overall, increased influence of the Southern Ocean on the deep ocean and a deeper pycnocline (Mechanism A) result in decreases in the efficiency of both biological and solubility pumps.

But what are the implications for air-sea $\mathrm{CO}_{2}$ fluxes and the meridional transport of carbon in the ocean? And how are air-sea $\mathrm{CO}_{2}$ fluxes connected to the carbon pumps? Again, we consider the effects of changing mixing on the abiotic, biotic and net fluxes.

The abiotic air-sea $\mathrm{CO}_{2}$ flux follows to first order the inverse of the thermal flux defined by Keeling et al. (1993) as: 

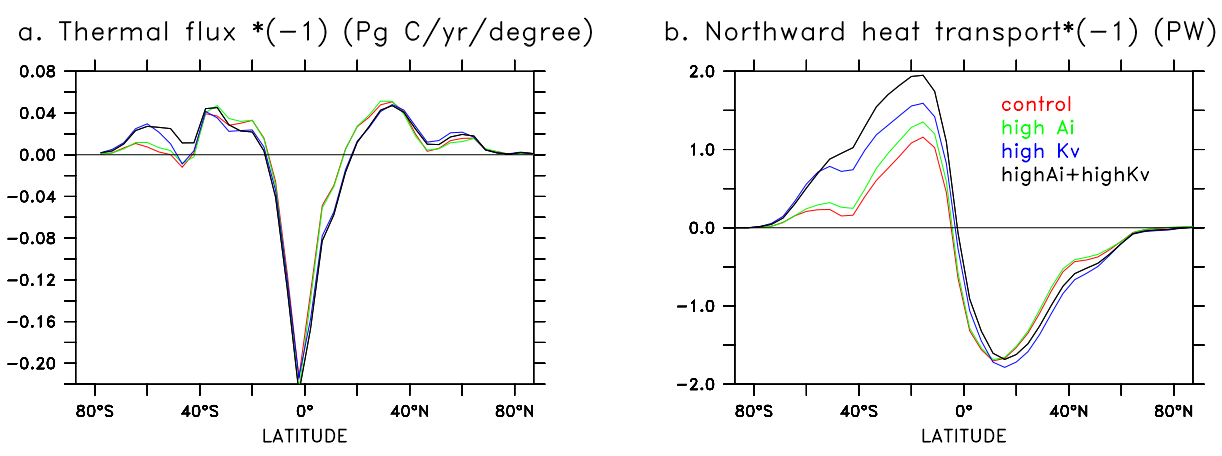

Fig. 4. (a) (-1) thermal flux in $\mathrm{Pg} \mathrm{Cyr}^{-1}$ degree $^{-1}$. (b) Southward heat transport (PW) in four different models with different mixing. All terms are annual and zonal averages. Thermal fluxes primarily reflect variations in heat fluxes and are calculated from Eq. (2) in the text, using a surface Revelle factor $R=14-0.2 \cdot T$ and assuming $1 / p \mathrm{CO}_{2} \cdot d p \mathrm{CO}_{2 \mathrm{eq}} / d T=0.0423^{\circ} \mathrm{C}^{-1}$ (Takahashi et al., 1993). Thermal fluxes drive the abiotic DIC fluxes in Fig. 1b. Southward heat transports drive the abiotic northward DIC transports in Fig. 1c.

$$
\begin{aligned}
F & =\frac{Q}{C_{p}} \cdot \frac{d \mathrm{DIC}_{\mathrm{eq}}}{d T}=\frac{Q}{C_{p}} \cdot \frac{\partial \mathrm{DIC}}{\partial p \mathrm{CO}_{2}} \cdot \frac{d p \mathrm{CO}_{2}}{d T} \\
& =\frac{Q}{C_{p} \cdot R} \cdot \frac{\mathrm{DIC}}{p \mathrm{CO}_{2}} \cdot \frac{d p \mathrm{CO}_{2}}{d T}
\end{aligned}
$$

where $Q$ is the heat flux from the atmosphere to the ocean, $C_{p}$ is the heat capacity of water, $T$ is temperature, and $R$ is the Revelle or buffer factor which shows the sensitivity of $p \mathrm{CO}_{2}$ to changes in DIC. This thermal flux primarily reflects variations in the heat flux (Fig. 4a) and drives the abiotic carbon fluxes in Fig. 1b, while the corresponding southward transport of heat (Fig. 4b) drives the abiotic northward transport of carbon in Fig. 1c.

Upwelling brings cold water to the surface at the Equator where it is heated up; the decrease in solubility results in loss of carbon to the atmosphere. As this water moves at the surface to higher latitudes in both hemispheres (e.g., through currents such as Gulf Stream, Kuroshio or through eddy diffusive transport) it gradually loses heat and gains $\mathrm{CO}_{2}$; low latitude outgassing is offset by $\mathrm{CO}_{2}$ ingassing in high latitudes.

The biological $\mathrm{CO}_{2}$ flux reflects the preformed nutrient distribution at the ocean surface. In high latitude regions such as the Southern Ocean, remineralized nutrients and carbon are upwelled to the surface. Since biological uptake is inefficient here relative to the upward supply, preformed nutrients and $p \mathrm{CO}_{2}$ at the ocean surface build up, resulting in $\mathrm{CO}_{2}$ outgassing to the atmosphere. Technically, the rate of biological outgassing to the atmosphere is controlled by the efficiency of conversion of deep remineralized nutrients to surface preformed nutrients; more surface preformed nutrients signal more inefficient biology and more biological outgassing.

At steady state, large biological uptake in the subtropics is required to counterbalance high latitude biological degassing. Biological uptake is generally efficient in the subtropics; translating into near-zero surface preformed nutrients and net uptake of carbon from the atmosphere. High export of organic matter at low latitudes is reflected by high remineralized nutrients and carbon right below the suface (with highest concentrations above $1000 \mathrm{~m}$ depth). From a nutrient budgeting perspective, we see a net conversion of preformed surface nutrients to remineralized sub-surface nutrients. This conversion controls the rate of biological carbon ingassing into the low latitude ocean.

The net air-sea $\mathrm{CO}_{2}$ exchange reflects a competition between biological and solubility effects, with the biological air-sea $\mathrm{CO}_{2}$ flux opposing the solubility air-sea $\mathrm{CO}_{2}$ flux throughout most of the ocean. In the low-latitudes, where preformed nutrients are low, the abiotic effect is much larger, and the air-sea flux reflects primarily the solubility flux. In the high latitudes, the two are much closer, and the solubility effect barely wins over the biological effect such that on average high latitudes are a sink for atmospheric $\mathrm{CO}_{2}$ (Fig. 1b, $\mathrm{e}, \mathrm{h})$. Interestingly, this is very different from the total carbon pump in the ocean (reflected by the DIC surface-to-deep gradients), which is dominated by the biological rather than the solubility pump (Fig. 1a, d, g).

In order to understand the impact of mixing on the airsea carbon exchange, it is easiest to think of the abiotic and biological air-sea carbon fluxes as the horizontal gradients of the abiotic and biological transports of carbon, respectively (Fig. 1c, f).

The depth integrated transport of abiotic carbon is a consequence of the net poleward heat transport in each hemisphere (Fig. 4b), and scales as the poleward water mass transport times the low latitude-high latitude temperature gradient. The biological meridional transport of carbon is given to a first order by the poleward transport of remineralized nutrients, adjusted by the appropriate stoichiometric constant, and scales as the poleward mass transport times the low latitudehigh latitude gradient in remineralized nutrients. In conclusion, we can understand changes in carbon transports in terms of changes in the poleward mass transport (referred to here as the residual mean circulation or $T_{S}$ in Fig. 2) and 
changes in the meridional gradients of temperature and remineralized nutrients.

The Southern Ocean residual mean circulation is a sum of the northwards Ekman advection and counteracting southward eddy transport. Changes in the residual mean circulation due to increased diapycnal mixing create a pattern in remineralized nutrients analogous to the temperature pattern, with increased values in sub-surface low latitudes and decreased Southern Ocean and deep ocean values (Fig. 3b and a). Increased diapycnal mixing increases the poleward residual mean circulation, transporting poleward both higher remineralized nutrients (and thus more biological DIC) and warmer tropical waters (and thus more heat). Additionally, the spatial correlation between the mixing-driven temperature change and remineralized nutrient change is 0.61 . Thus, insofar as the increase in poleward heat transport is due to warming of the thermocline waters, there is a corresponding increase in the poleward transport of biological carbon due to a higher concentration of remineralized nutrient in the thermocline. The resulting increase in poleward transport of biological DIC compensates almost exactly the increase in equatorward solubility driven (abiotic) DIC, such that total carbon transport and resulting air-sea $\mathrm{CO}_{2}$ fluxes do not change much with mixing (Fig. 1h, i).

Revisiting Fig. 1, we see that changing isopycnal mixing $A_{\mathrm{i}}$ has a much smaller effect on carbon pumps and air-sea fluxes than diapycnal mixing $K_{\mathrm{v}}$. An increase in $A_{\mathrm{i}}$ decreases on average the large scale overturning circulation, decreases equatorial upwelling and inhibits the large oceanic cooling associated with the Western Boundary Current. Therefore, changes in the abiotic air-sea $\mathrm{CO}_{2}$ flux due to increasing $A_{\mathrm{i}}$ can locally oppose changes in fluxes due to increasing $K_{\mathrm{v}}$.

The compensation between different pumps occurs despite large impacts of mixing on individual pumps. Increasing $K_{\mathrm{V}}$ from 0.15 to $0.6 \mathrm{~cm}^{2} \mathrm{~s}^{-1}$ increases the poleward heat transport by $0.8 \mathrm{PW}$ in the Southern Hemisphere and $0.2 \mathrm{PW}$ in the Northern Hemisphere (Gnanadesikan et al., 2003) and the peak poleward biological carbon transport by $0.6 \mathrm{Pg} \mathrm{C} \mathrm{yr}^{-1}$ in the Southern Hemisphere. Lateral diffusion has a smaller impact, increasing poleward heat transport in the Southern Hemisphere by up to $0.4 \mathrm{PW}$ and reducing it in the Northern Hemisphere, with correspondingly smaller impacts on the carbon transport.

A final point which we wish to highlight is the dominant role of the Southern Hemisphere. For example, the changes in heat transports are 2-4 times as strong in the Southern compared to the Northern Hemisphere. Similarly, the sensitivity of both abiotic and biological fluxes to changes in subgridscale mixing or wind intensity is highest in the Southern Ocean. The dominance of Southern Hemisphere impacts is also found for changes in wind intensity (not shown here). This is also consistent with the results of Sarmiento et al. (1998) who find large sensitivity in the Southern Ocean biological and abiotic fluxes to changes in stratification following climate change. It is thus not surprising that when
Watson and Orr (2003) analyzed a set of models with identical (OCMIP) biogeochemistry but different model physics and different boundary conditions, they found the largest disagreement between biological, solubility and anthropogenic $\mathrm{CO}_{2}$ air-sea fluxes in the Southern Ocean.

\section{Conclusions}

We have shown that increasing mixing decreases both the solubility and the biological carbon pumps and carbon storage in the ocean but has little impact on the total air-sea $\mathrm{CO}_{2}$ flux. The difference arises because different parts of the ocean circulation are responsible for setting the magnitude of the carbon pumps and fluxes. AABW formation plays a critical role in setting the inventory of carbon and the magnitude of the net carbon pumps. By contrast, air-sea $\mathrm{CO}_{2}$ fluxes depend on the transport of warm waters with higher remineralized nutrients from low to high latitudes. Changes in the solubility $\mathrm{CO}_{2}$ flux with vertical mixing are explained by underlying changes in temperature and meridional heat transport, while changes in the biological $\mathrm{CO}_{2}$ flux with vertical mixing mirror changes in remineralized nutrients and their meridional transport. As a result, we observe a strong compensation between changes in the biological and solubility $\mathrm{CO}_{2}$ fluxes and transports such that the total flux and the corresponding total meridional transport remain largely unchanged (Fig. 1h, i).

To some extent the compensation mechanism is fortuitous because the present sizes of the remineralized pool of nutrients and the current temperature gradient are such that mixing-induced changes in the meridional gradients of nutrient and temperature have comparable and opposite impacts on carbon. If the compensation mechanism were to hold true in the real ocean, potential changes in circulation due to climate change, while strongly affecting the individual pump strength and the natural carbon sequestration in the deep ocean, would not have an observable impact on the total $\mathrm{CO}_{2}$ fluxes and the meridional transport of natural carbon. However, changes that affected only the biological pump (such as changing iron supply to the surface ocean) would result in air-sea $\mathrm{CO}_{2}$ fluxes that did depend strongly on circulation. This can be seen by recognizing that if nutrients were depleted to zero everywhere at the ocean surface (following iron fertilization) the biological air-sea flux of carbon would vanish, leaving only the solubility-driven fluxes which (as shown in Fig. 1b and c) do differ significantly between different circulation models.

Research has suggested that SST differences between GCMs forced with different winds are amplified in coupled simulations compared to ocean only models such as ours where atmospheric temperature is held fixed (Gnanadesikan and Anderson, 2009). We might therefore expect an even larger response of abiotic and biological $\mathrm{CO}_{2}$ fluxes and carbon pumps to changes in winds or mixing in coupled models. 
The existence of a compensation mechanism between solubility and biological carbon fluxes might thus be even more important and needs to be further tested in such coupled setups.

Acknowledgements. I. Marinov was supported by NOAA grant NA10OAR4310092. We thank Jorge Sarmiento and Robbie Toggweiler for useful discussions. We also thank Rick Slater and Roman Shor for technical support.

Edited by: V. Brovkin

\section{References}

Anderson, R. F., Ali, S., Bradtmiller, L. I., Nielsen, S. H. H., Fleisher, M. Q., Anderson, B. E., and Burckle, L. H.: Winddriven upwelling in the Southern Ocean and the deglacial rise in atmospheric $\mathrm{CO}_{2}$, Science, 323(5920), 1443-1448, doi:10.1126/science.1167441, 2009.

da Silva, C., Young C., and Levitus, S.: Atlas of Surface Marine Data 1994, Vol. 1: Algorithms and Procedures, NOAA Atlas NESDIS 6, US Dept. of Commerce, Washington, DC, 1994.

Gnanadesikan, A.: A simple predictive model for the structure of the oceanic pycnocline, Science, 283(5410), 2077-2079, 1999.

Gnanadesikan, A. and Anderson, W. G.: Ocean water clarity and the ocean general circulation in a coupled climate model, J. Phys. Oceanogr., 39, 314-332, 2009.

Gnanadesikan, A., Slater, R. D., Gruber, N., and Sarmiento, J. L.: Oceanic vertical exchange and new production: a comparison between models and observations, Deep-Sea Res. Pt. II, 49, 363401, 2002.

Gnanadesikan, A., Slater, R. D., and Samuels, B. L.: Sensitivity of water mass transformation and heat transport to subgridscale mixing in coarse-resolution ocean models, Geophys. Res. Lett., 30(18), 1967, doi:10.1029/2003GL018036, 2003.

Gnanadesikan, A., Dunne, J. P., Key, R. M., Matsumoto, K., Sarmiento, J. L., Slater, R. D., and Swathi, P. S.: Oceanic ventilation and biogeochemical cycling: Understanding the physical mechanisms that produce realistic distributions of tracers and productivity, Global Biogeochem. Cy., 18(4), GB4010, doi:10.1029/2003GB002097, 2004.

Hellerman, S. and Rosenstein, M.: Normal monthly wind stress over then World Ocean with error estimate, J. Phys. Oceanogr., 13, 1093-1104, 1983.

Ito, T. and Follows, M. J.: Preformed phosphate, soft tissue pump and atmospheric $\mathrm{CO}_{2}$, J. Mar. Res., 63(4), 813-839, doi:10.1357/0022240054663231, 2005.

Keeling, R. F., Najjar, R. P., Bender, M. L., and Tans, P. P.: What atmospheric oxygen measurements can tell us about the global carbon-cycle, Global Biogeochem. Cy., 7(1), 37-67, 1993.

Le Quere, C., Rodenbeck, C., Buitenhuis, E. T., Conway, T. J., Langenfelds, R., Gomez, A., Labuschagne, C., Ramonet, M., Nakazawa, T., Metzl, N., Gillett, N., and Heimann, M.: Saturation of the Southern Ocean $\mathrm{CO}_{2}$ sink due to recent climate change, Science, 316(5832), 1735-1738, doi:10.1126/science.1136188, 2007.

Marinov, I., Gnanadesikan, A., Toggweiler, R., and Sarmiento, J. L.: The Southern Ocean Biogeochemical Divide, Nature, (441), 946-967, doi:10.1038/nature04883, 2006.
Marinov, I., Follows, M., Gnandesikan, A., Sarmiento, J. L., and Slater, R. D.: How does ocean biology affect atmospheric $p \mathrm{CO}_{2}$ ? Theory and Models, J. Geophys. Res.-Oceans, 113, C07032, doi:10.1029/2007JC004598, 2008a.

Marinov, I., Gnanadesikan, A., Sarmiento, J. L., Toggweiler, R., Follows, M., and Mignone, B.: Impact of oceanic circulation on the biological carbon storage in the ocean and atmospheric $p \mathrm{CO}_{2}$, Global Biogeochem. Cy., 22, GB3007, doi:10.1029/2007GB002958, 2008b.

Murnane, R. J., Sarmiento, J. L., and LeQuere, C.: Spatial distribution of air-sea fluxes and the interhemispheric transport of carbon by the oceans, Global Biogeochem. Cy., 13(2), 287-305, 1999.

Najjar, R. G., Jin, X., Louanchi, F., Aumont, O., Caldeira, K., Doney, S. C., Dutay, J.-C., Follows, M., Gruber, N., Joos, F., Lindsay, K., Maier-Reimer, E., Matear, R. J., Matsumoto, K., Monfray, P., Mouchet, A., Orr, J. C., Plattner, G.-K., Sarmiento, J. L., Schlitzer, R., Slater, R. D., Weirig, M.-F., Yamanaka, Y., and Yool, A.: Impact of circulation on export production, dissolved organic matter, and dissolved oxygen in the ocean: Results from PhaseII of the Ocean Carbon-cycle Model Intercomparison Project (OCMIP 2), Global Biogeochem. Cy., 21(3), GB3007, 10.1029/2006GB002857, 2007.

Sarmiento, J. L. and Toggweiler, J. R.: A new model for the role of the oceans in determining atmospheric $p \mathrm{CO}_{2}$, Nature, 308, 620-624, 1984.

Sarmiento, J. L., Hughes, T. M. C., Stouffer, R. J., and Manabe, S.: Simulated response of the ocean carbon cycle to anthropogenic climate warming, Nature, 393, 245-249, 1998.

Sigman, D., Hain M., and Haug, G.: The polar ocean and glacial cycles in atmospheric $\mathrm{CO}_{2}$ concentration, Nature, 466, 47-55, 2010.

Takahashi, T., Olafsson, J., Goddard, J. G., Chipman, D. W., and Sutherland, S. C.: Seasonal variation of $\mathrm{CO}_{2}$ and nutrients in the high-latitude surface oceans: A comparative study, Global Biogeochem. Cy., 7(4), 843-878, doi:10.1029/93GB02263, 1993.

Takahashi, T., Sutherland, S. C., Wanninkhof, R., Sweeney, C., Feely, R. A., Chipman, D. W., Hales, B., Friederichg, G., Chavez, F., Sabine, C., Watson, A., Bakker, D. C. E., Schuster, U., Metzl, N., Yoshikawa-Inoue, H., Ishii, M., Midorikawa, T., Nojiri, Y., Körtzinger, A., Steinhoff, T., Hoppema, M., Olafsson, J., Arnarson, T. S., Tilbrook, B., Johannessen, T., Olsen, A., Bellerby, R., Wong, C. S., Delille, B., Bates, N. R., and de Baar H. J. W.: Climatological Mean and Decadal Change in Surface Ocean $\mathrm{pCO}_{2}$, and Net Sea-air $\mathrm{CO}_{2}$ Flux over the Global Oceans, Deep-Sea Res. Pt. II, 56(8-10), 554-577, 2009.

Toggweiler, J. R., Gnanadesikan, A., Carson, S., Murnane, R., and Sarmiento, J. L.: Representation of the carbon cycle in box models and GCMs: 1. Solubility pump, Global Biogeochem. Cy., 17, 1026, doi:10.1029/2001GB001401, 2003a.

Toggweiler, J. R., Murnane, R., Carson, S., Gnanadesikan, A., and Sarmiento, J. L.: Representation of the carbon cycle in box models and GCMs: 1. Organic pump, Global Biogeochem. Cy., 17, 1027, doi:10.1029/2001GB001841, 2003b.

Toggweiler, J. R., Russell, J. L., and Carson, S. R.: Midlatitude westerlies, atmospheric $\mathrm{CO}_{2}$ and climate change during the Ice Ages, Paleoceanography, 21, PA2005, doi:10.1029/2005PA001154, 2006.

Volk, T. and Hoffert, M. I.: Ocean carbon pumps: Analysis of relative strengths and efficiencies in ocean driven atmospheric $\mathrm{CO}_{2}$ 
changes, in: The Carbon Cycle and Atmospheric $\mathrm{CO}_{2}$ : Natural variations Archaean to present, edited by: Sundquist, E. T. and Broecker, W. S., Geoph. Monog. Series, AGU, Washington, D.C., 32, 99-110, 1985.

Wanninkhof, R.: Relationship between gas exchange and wind speed over the ocean, J. Geophys. Res., 97, 7373-7382, 1992.
Watson, A. J. and Orr, J. C.: Carbon dioxide fluxes in the global ocean, Chapter 5, in: Ocean Biogeochemistry: the Role of the Ocean Carbon Cycle in Global Change (a JGOFS Synthesis), edited by: Fasham, M., Field, J., Platt, T., and Zeitzschel, B., Springer, Berlin, 123-141, 2003. 